University of Wollongong

Research Online

Faculty of Engineering and Information

Faculty of Engineering and Information

Sciences - Papers: Part A

Sciences

$1-1-2014$

Optimal design of vertical ground heat exchangers by using entropy generation minimization method and genetic algorithms

Su Huang

University of Wollongong, sh377@uowmail.edu.au

Zhenjun $\mathrm{Ma}$

University of Wollongong, zhenjun@uow.edu.au

Paul Cooper

University of Wollongong, pcooper@uow.edu.au

Follow this and additional works at: https://ro.uow.edu.au/eispapers

Part of the Engineering Commons, and the Science and Technology Studies Commons

Research Online is the open access institutional repository for the University of Wollongong. For further information contact the UOW Library: research-pubs@uow.edu.au 


\title{
Optimal design of vertical ground heat exchangers by using entropy generation minimization method and genetic algorithms
}

\begin{abstract}
This paper presents the development and validation of an optimal design methodology for vertical U-tube ground heat exchangers (GHEs) used in HVAC systems. The dimensionless entropy generation number obtained by scaling the entropy generation due to heat transfer and pressure drop, on the ratio of the heat transfer rate to the average fluid temperature of vertical GHEs is employed as the objective function. Five design variables are first selected based on the global sensitivity analysis and then optimized by a genetic algorithm optimization technique. The entropy generation process combines the heat transfer and fluid mechanics with thermodynamic analysis. A case study shows that this optimal design approach can decrease the total system cost (i.e. the upfront cost and 10 -year operation cost) by $5.5 \%$, compared with the original design. The entropy generation number (EGN) of the optimal design case is $12.2 \%$ less than that of the base design case. From the thermo-economic aspect, decreasing the upfront cost is more important than decreasing the operational cost for the case studied. The results also demonstrate the effectiveness and feasibility of using the entropy generation minimization method for optimal design of vertical GHEs.
\end{abstract}

\section{Keywords}

genetic, method, minimization, algorithms, generation, exchangers, entropy, heat, ground, optimal, design, vertical

Disciplines

Engineering | Science and Technology Studies

\section{Publication Details}

Huang , S., Ma, Z. \& Cooper, P. (2014). Optimal Design of Vertical Ground Heat Exchangers by Using Entropy Generation Minimization Method and Genetic Algorithms. Energy Conversion and Management, 87 128-137. 


\title{
Optimal Design of Vertical Ground Heat Exchangers by Using Entropy Generation Minimization Method and Genetic Algorithms
}

\author{
Su Huang, Zhenjun Ma*, Paul Cooper \\ Sustainable Buildings Research Centre (SBRC), Faculty of Engineering and Information \\ Sciences, University of Wollongong, New South Wales, 2522, Australia \\ *Corresponding Author: Phone: 6102 4221 4143; Email: Zhenjun@uow.edu.au
}

\begin{abstract}
This paper presents the development and validation of an optimal design methodology for vertical U-tube ground heat exchangers (GHEs) used in HVAC systems. The dimensionless entropy generation number obtained by scaling the entropy generation due to heat transfer and pressure drop, on the ratio of the heat transfer rate to the average fluid temperature of vertical GHEs is employed as the objective function. Five design variables are first selected based on the global sensitivity analysis and then optimized by a genetic algorithm optimization technique. The entropy generation process combines the heat transfer and fluid mechanics with thermodynamic analysis. A case study shows that this optimal design approach can decrease the total system cost (i.e. the upfront cost and 10-year operation cost) by $5.5 \%$, compared with the original design. The entropy generation number (EGN) of the optimal design case is $12.2 \%$ less than that of the base design case. From the thermoeconomic aspect, decreasing the upfront cost is more important than decreasing the operational cost for the case studied. The results also demonstrate the effectiveness and feasibility of using the entropy generation minimization method for optimal design of vertical GHEs.
\end{abstract}

Keywords: Design optimization; Ground heat exchangers; Entropy generation; Genetic algorithm; Case study 


\begin{tabular}{|c|c|c|c|}
\hline \multicolumn{4}{|c|}{ Nomenclature } \\
\hline GHE & ground heat exchanger & $q$ & heat transfer rate $(\mathrm{W} / \mathrm{m})$ \\
\hline GSHP & ground source heat pump & $m_{f}$ & mass flow rate $(\mathrm{kg} / \mathrm{s})$ \\
\hline$E G M$ & entropy generation minimization & $r$ & radius $(\mathrm{m})$ \\
\hline$E G N$ & entropy generation number & $\rho$ & density $\left(\mathrm{kg} / \mathrm{m}^{3}\right)$ \\
\hline GSA & global sensitivity analysis & $k$ & thermal conductivity (W/mK) \\
\hline$T A C$ & total annual cost $(\$)$ & $f$ & friction number \\
\hline$I C$ & upfront cost (\$) & $h$ & convective heat transfer coefficients $\left(\mathrm{W} / \mathrm{m}^{2} \mathrm{~K}\right)$ \\
\hline$O C$ & operating cost $(\$)$ & $c$ & specific heat $(\mathrm{J} / \mathrm{kgK})$ \\
\hline$C$ & $\operatorname{cost}(\$)$ & $\mu$ & dynamic viscosity (kg/ms) \\
\hline$Q$ & design load (W) & & \\
\hline$L$ & depth $(m)$ & \multicolumn{2}{|c|}{ Subscripts } \\
\hline$T$ & temperature $(\mathrm{K})$ & $b$ & borehole/borehole wall \\
\hline$\Delta T$ & temperature difference $(\mathrm{K})$ & $p$ & U-tube pipe \\
\hline$N$ & borehole number & $f$ & Fluid \\
\hline$D$ & half shank space (m) & $s$ & Soil \\
\hline$B$ & borehole distance (m) & 0 & environmental condition \\
\hline$S_{\text {gen }}$ & entropy generation rate $(\mathrm{W} / \mathrm{K})$ & 1 & inlet of U-tube pipe \\
\hline$N_{s}$ & dimensionless entropy number & 2 & outlet of U-tube pipe \\
\hline$R$ & thermal resistance $(\mathrm{mK} / \mathrm{W})$ & $i$ & Inner \\
\hline$\Delta P$ & pressure drop $(\mathrm{Pa})$ & $o$ & Outer \\
\hline$N u$ & Nusselt number & $m$ & Average \\
\hline$R e$ & Reynolds number & tot & total \\
\hline$\tau$ & time (s) & & \\
\hline
\end{tabular}




\section{Introduction}

The increasing demand on energy supply, in conjunction with global warming due to the greenhouse gas emissions from the use of fossil fuels, has led to the rapid development of low energy technologies for building heating and cooling applications [1-3]. Ground source heat pumps (GSHPs) with high energy efficiency and low greenhouse gas emissions have been recognized as one of the most sustainable and environmentally friendly solutions for heating and cooling of both residential and commercial buildings [4-6]. It is reported that reductions in energy consumption of $30-70 \%$ in the heating mode and $20-50 \%$ in the cooling mode can be achieved through proper use of GSHPs to replace conventional air-conditioning systems [7]. GSHPs are gaining market share with an annual increase rate of $10-30 \%$ in recent years [8]. In spite of their popularity, high installation cost, installation infrastructure limitations and system design are the main challenges preventing the wide application of GSHP systems in buildings [9]. In particular, the high installation cost makes the short-term economics unattractive $[5,9]$.

Over the last two or more decades, significant efforts have been made on the development of GSHPs in building applications and various issues such as system design, component modeling, capacity control, load imbalance and thermal performance optimization have been addressed in various studies. For instance, Garber et al. [10] proposed a methodology to evaluate the financial risk due to the over-size of ground heat exchangers. Zogou and Stamatelos [11] presented the optimization of the thermal performance of buildings integrated with GSHPs using TRNSYS. It was concluded that detailed simulation can allow better assessment of the effects of control settings and system characteristics. Yu et al. [12] experimentally evaluated a constant temperature and humidity air-conditioning system driven by GSHPs in Shanghai, China. The suggested borehole distance is in the range of $4-5 \mathrm{~m}$. Pertzborn et al. [13] investigated the impact of weather variations on the design of GSHP 
systems. A comprehensive review on the design of borehole heat exchangers for GSHPs can be found in [14]. Alavy et al. [15] proposed a new methodology for optimization of the capacity of GSHPs in hybrid systems in terms of the net present value. The results indicated that, in most cases, the GSHPs need to meet around $80 \%$ of the total design load of the hybrid system. Robert and Gosselin et al. [16] developed a new design method to determine the optimal borehole number, borehole distance and depth, and the optimal size of heat pumps, based on the total cost minimization method. However, in above two new design studies, the optimization was performed based on the economic aspect, and the thermodynamic performance of the ground heat exchangers (GHEs) was not the main design target.

There are some studies focusing on investigating the thermodynamic performance of GSHP systems in terms of exergy analysis. Hepbsali and Akdemir [17], for instance, performed a detailed energy and exergy analysis of a GSHP system. The result indicated that detailed exergy analysis is able to provide quantitative information for the proportion of the exergy input that is dissipated in various components, which was important for system optimization. The comprehensive exergy analysis performed by Bi et al. [18] showed that the GHEs normally have minimum exergy efficiency and thermodynamic perfection, indicating great potential of design optimization from the aspect of thermodynamic performance.

In order to facilitate better design of GSHP systems, efforts have also been made on the development of design optimization methods by taking into consideration of thermodynamic perfection. Sayyaadi et al. [19] carried out a multi-objective optimization of GSHP systems for reducing both the cost and exergy destruction associated with the use of GSHPs. Sayyadi and Nejatolahi [20] further performed a thermodynamic and thermo-economic optimization of a cooling tower-assisted GSHP system, in which a genetic algorithm was used as the optimization technique. Min and Lai [21] applied the entropy generation minimization (EGM) 
method for the design optimization of a vertical GHE. In their study, the analytical expressions were developed to determine both the optimal borehole depth and flow velocity.

The EGM, or thermodynamic optimization, is a method for modelling and optimization of thermodynamic cycles, which has been widely applied to the optimization design of heat exchangers $[22,23]$. Minimization of the entropy generation of a system is equivalent to the optimization of its thermodynamic performance. Usually, the application of EGM is referred as entropy generation number (EGN), which is defined by scaling the entropy generation rate on the heat capacity rate [22].

In this paper, the entropy generation minimization and genetic algorithms are used to formulate an optimal design methodology for vertical U-tube ground heat exchangers (GHEs). In this methodology, the entropy generation number (EGN) is defined as the objective function, and the infinite line source model is utilized for performance prediction. The global sensitivity analysis is used to determine the non-influential design parameters to reduce the number of decision variables. Genetic algorithm is used as the optimization technique to solve the optimization problem and search for optimal values of major design parameters. An illustrative example is used to validate the effectiveness of the proposed optimal design methodology.

\section{Formulation and development of the optimal design methodology}

\subsection{Outline of the optimal design methodology}

The aim of the thermodynamic modelling of vertical U-tube ground heat exchangers is to evaluate and compare the thermal performance of alternative design options. Fig. 1 illustrates the block diagram of the optimal design methodology. The overall optimization procedure consists of two steps. The first step is to use a global sensitivity analysis method to determine the major design parameters and their design constraints. The second step is to formulate the entropy generation minimization method (EGM)-based optimization strategy, including the 
development of the objective function, and selection of the performance model and optimization technique.

Genetic algorithm (GA) as an optimization tool can provide good solutions with random initialization and has been widely used to solve the optimization problems in engineering and science fields $[24,25]$. The algorithm is maintained by a population of parent individuals that represent the latent solutions of a real-world problem. After some generations, the algorithm converges to a best individual, which probably represents the best or nearly optimal solution of the given problem [24, 25]. A GA optimizer is used in this study to search for optimal values of major design parameters. The GA was implemented by using MATLAB Optimization Toolbox [26].

\subsection{Objective function and design constraints}

\subsubsection{Objective function}

The major objective of the optimization in this study is to minimize the thermodynamic irreversibility due to the friction fluid flow and heat transfer driven by the finite temperature difference in the vertical GHEs. This will be achieved through identification of the optimal design values of vertical U-tube GHEs which are capable of accomplishing the designed thermal duty with minimum thermodynamic irreversibility. The objective function is denoted by the so-called entropy generation number (EGN) method generated based on the entropy generation rate $S_{g e n}$, and is expressed in equation (1) [22]:

$$
N_{s}=\frac{S_{g e n} \cdot T_{f, m}}{Q}
$$

where, $N_{s}$ is the dimensionless entropy generation number, $S_{g e n}$ is the entropy generation rate, $T_{f, m}$ is the average fluid temperature of the vertical U-tube GHE, and $Q$ is the heat transfer rate.

The detailed procedure to be used to calculate the entropy generation rate $\left(S_{g e n}\right)$ of the vertical U-tube GHEs will be presented in section 3. 


\subsubsection{Design constraints}

Mathematical models used in the optimization process are typically simplified to represent the real process. Both the model mismatch and process disturbance can result in infeasible operation conditions. Hence, defining the constraints of the decision parameters is crucial in helping avoid this potential problem [27]. In this study, the following constraints were applied in the optimization process.

1) Constraints for geometrical parameters: the variation ranges of the geometrical parameters such as the number of boreholes, borehole depth, borehole distance, etc., as shown in Fig. 2, were determined based on the recommended values of practical engineering projects and summarized in Table 1 [28, 29].

2) Constraints for heat transfer process: the estimated total length of the vertical GHEs is associated with the possible maximal heat flux. The acceptable range of the maximal heat flux is dependent on the thermal conductivity of the soil on the site [29]. In this study, the acceptable range of the maximal heat flux $(30 \mathrm{~W} / \mathrm{m}-130 \mathrm{~W} / \mathrm{m})$ recommended by Robert and Gosselin [16] was used.

3) Temperature constraints: the maximum and minimum outlet temperatures from the vertical GHEs in the cooling and heating conditions have a fairly limited range of acceptable values. The practical values of the temperature constraints were normally dependent on the mode of the heat pump used [28]. The minimum entering fluid temperature to the heat pump at the design condition in the heating condition can be determined by Equation (2), while the maximum entering fluid temperature to the heat pump at the design condition in the cooling condition can be determined by Equation (3) [28].

$$
\begin{gathered}
T_{f, 2, \text { min }}=T_{s, \text { min }}-8.3^{\circ} \mathrm{C} \\
T_{f, 2, \text { max }}=\min \left(T_{\mathrm{s}, \text { max }}+11.1^{\circ} \mathrm{C}, 43.3^{\circ} \mathrm{C}\right)
\end{gathered}
$$


where, $T_{f, 2}$ is the outlet fluid temperature from the vertical U-tube GHE, $T_{s, \min }$ is the minimal soil temperature over the year, and $T_{s, \max }$ is the maximal soil temperature over the year. The average soil temperature was assumed as $20^{\circ} \mathrm{C}$ with a temperature variation of $5^{\circ} \mathrm{C}$.

\subsection{Sensitivity analysis}

Design of the vertical GHEs depends on a number of parameters such as the borehole depth, borehole numbers, borehole radius, U-tube diameter, etc. All these parameters affect the thermal irreversibility output. Since sensitivity analysis has been widely used to understand the relationships of input parameters on different simulation outputs [30], a global sensitivity analysis is performed in this study to screen the design parameters with a significant impact on the thermal irreversibility output.

The Sobol' method, which is a variance-based global sensitivity technique, is used in this study. The Sobol' method can test the contribution of each input parameter to the variance of the output [30]. The method can be represented in the form of Equation (4) [31].

$$
Y=f\left(x_{1}, x_{2} \ldots, x_{k}\right)
$$

where, $Y$ is the model output, and $x_{1}, x_{2}, \ldots, x_{k}$ are the input factors. In this study, $Y$ is the dimensionless entropy generation number, and $x_{1}, x_{2}, \ldots, x_{k}$ represent the design parameters listed in Table 1.

The total variance can be determined by Equation (5), which will be used to derive the total sensitivity index in Equation (6) and used as the measurement index in this study [31].

$$
\begin{gathered}
V(Y)=\sum_{i=1}^{k} V_{i}+\sum_{1<i<j \leq k}^{k} V_{i j} \ldots+V_{1,2, \ldots k} \\
S_{i}^{t o t}=1-\frac{V_{-i}}{V(Y)}
\end{gathered}
$$

where, $V(Y)$ is the total variance of the output $Y, V_{i}$ measures the main effect of the parameter $x_{i}, V_{i j}$ and $V_{1,2, \ldots, k}$ measure the interaction effects between the parameter $x_{i}$ and the other 
parameters, $V_{-i}$ is the sum of all variance terms that exclude the index $i$, and $S_{i}^{\text {tot }}$ is the total sensitivity index for $x_{i}$ which takes into account all effects including the parameter $x_{i}$.

The successful use of the Sobol' global sensitivity analysis method is related to the possibility of computing the multi-dimensional integrals. Usually, Monte Carlo method based on the probabilistic interpretation of an integral is used to generate the randomly samples of the parameters within the permissible ranges to compute the Sobol' indices. The samples of the parameters can be generated by matrix and the sensitivity indices are computed based on the scalar products of the defined vectors of the model outputs [31]. The principle of Monte Carlo method and the detailed generation procedures can be found in [31].

\section{Energy modelling}

\subsection{Heat transfer calculation}

There are many methods of simulating the heat transfer process in and around a vertical GHE [8]. Practically, the heat transfer process of a vertical GHE is analyzed in two separated zones. One is the soil/rocks outside the borehole. The other is the zone inside the borehole, including the grout, U-tube pipes and the circulating fluid inside the pipes as shown in Fig. 2. The analytical model representing the heat transfer process of the vertical U-tube GHEs used in this study consists of the infinite line source model, and the thermal resistance of boreholes derived from the line-source approximation which is used in the well-known duct ground heat storage model [32].

The infinite line source model was developed based on Kelvin's line source theory [8]. The whole borehole is considered as a semi-infinitely long line source in the ground which is regarded as an infinite medium with an initial uniform temperature. This model has been widely utilized in analytical design methods to analyze the heat transfer of GHEs [8]. The model can provide acceptable prediction when the simulation time $(\tau)$ is larger than $20 r_{b}{ }^{2} / a_{s}$. Otherwise, it may result in significant errors [8]. In the vicinity of the borehole, for 
sufficiently long time scales and constant heat flux, the infinite line source model gives the expression below to determine the borehole wall temperature $T_{b}$.

$$
\begin{gathered}
T_{b}=T_{s}\left(r_{b}, \tau\right)=T_{s, 0}+\frac{q}{4 \pi k_{s}} \int_{\frac{r_{r}^{2}}{4 \alpha_{s} \tau}}^{\infty} \frac{e^{-u}}{u} d u \cong T_{s, 0}+\frac{q}{4 \pi k_{s}} E_{1}\left(\frac{r_{b}^{2} \rho_{s} c_{s}}{4 k_{s} \tau}\right) \\
q=\frac{Q}{N L_{b}}
\end{gathered}
$$

where, $T_{s, 0}$ is the undisturbed soil temperature, $r_{b}$ is the borehole radius, $q$ is the heat flux, $k_{s}$ is the soil thermal conductivity, $\alpha_{s}$ is the thermal diffusivity, $\tau$ is the simulation time, $E_{1}(x)$ is the exponential integral function, $N$ is the borehole number, $L_{b}$ is the borehole depth, $\rho_{s}$ is the soil density, and $c_{s}$ is the specific heat of the soil.

Borehole thermal resistance is an important parameter in the determination of the inlet and outlet fluid temperatures of the vertical GHEs. The borehole thermal resistance driven by the line-source approximation can be determined by Equation (9) $[32,33]$.

$$
\begin{gathered}
R_{b}=\frac{1}{4 \pi k_{b}}\left[\ln \frac{r_{b}}{r_{o}}+\ln \frac{r_{b}}{2 D}+\frac{k_{b}-k_{s}}{k_{b}+k_{s}} \ln \left(\frac{r_{b}^{4}}{r_{b}^{4}-D^{4}}\right)\right]+\frac{R_{p}}{2} \\
R_{p}=\frac{1}{2 \pi k_{p}} \ln \frac{r_{o}}{r_{i}}+\frac{1}{2 \pi r_{i} h_{f}}
\end{gathered}
$$

where, $R_{b}$ is the total borehole thermal resistance, $R_{p}$ is the pipe thermal resistance, $r_{i}$ and $r_{o}$ the inner and outer radius of the U-tube, $D$ is the half shank space, $h_{f}$ is the convective heat transfer coefficient, $k_{b}$ is the thermal conductivity of grout material, and $k_{p}$ is the thermal conductivity of U-tube.

The convective heat transfer coefficient $\left(h_{f}\right)$ is determined by Nusselt number described in Equations (11) and (12) [34].

For laminar flows:

$$
N u=\frac{2 h_{f} r_{i}}{k_{f}}= \begin{cases}4.36 & \text { for uniform heat flux } \\ 3.66 & \text { for uniform wall temperature }\end{cases}
$$


For fully developed turbulent flows:

$$
N u=\frac{2 h_{f} r_{i}}{k_{f}}=0.023 \operatorname{Re}^{0.8} \operatorname{Pr}^{0.3},\left(0.7<\operatorname{Pr}<160 ; \operatorname{Re}>10^{4}\right)
$$

The thermal resistance between the borehole wall and the undisturbed soil layer $\left(R_{S}\right)$ can be derived as Equation (13) and the thermal resistance for multiple boreholes connected in parallel can be determined by Equation (14) $[32,33]$.

$$
\begin{gathered}
R_{s}=\frac{1}{4 \pi k_{s}} E_{1}\left(\frac{r_{b}^{2} \rho_{s} c_{s}}{4 k_{s} \tau}\right) \\
R_{s, N}=\frac{1}{4 \pi k_{s}}\left[E_{1}\left(\frac{r_{b}^{2} \rho_{s} c_{s}}{4 k_{s} \tau}\right)+\sum_{i=2}^{N} E_{1}\left(\frac{B_{i}^{2} \rho_{s} c_{s}}{4 k_{s} \tau}\right)\right]
\end{gathered}
$$

where, $R_{S}$ and $R_{s, N}$ are the soil thermal resistance for single borehole and multiple boreholes, and $B_{i}$ is the borehole distance.

The temperature difference between the circulated fluid $T_{f}$ and undistributed ground temperature $T_{s, 0}$ for single borehole and multiple boreholes can be expressed in Equation (15) and Equation (16), respectively.

$$
\begin{aligned}
& T_{f}(\tau) \cong T_{s, 0}+q\left\{R_{s}+R_{b}\right\} \\
& T_{f}(\tau) \cong T_{s, 0}+q\left\{R_{s, N}+R_{b}\right\}
\end{aligned}
$$

where, $T_{f}$ is the arithmetic mean circulating fluid temperature, defined in Equation (17).

$$
T_{f}=\frac{T_{f, 1}+T_{f, 2}}{2}
$$

where, $T_{f, 1}$ and $T_{f, 2}$ are inlet and outlet fluid temperatures of the vertical U-tube GHE.

3.2 Pressure drop calculation

The pressure drop $(\Delta P)$ along a single U-tube pipe can be determined by Equation (18) [21].

$$
\Delta P=f \frac{m_{f}^{2}\left(2 L_{b}\right)}{\rho_{f} \pi^{2} r_{i}^{5}}
$$


where, $f$ is the friction factor, $m_{f}$ is the mass flow rate per U-tube pipe. The friction number $f$ is determined by the following well-known correlations [34].

For laminar pipe flow:

$$
f \cong \frac{16}{\operatorname{Re}}
$$

For fully developed turbulent pipe flow:

$$
f \cong 0.046 \operatorname{Re}^{-0.2},\left(10^{4}<\operatorname{Re}<10^{6}\right)
$$

where, $R e$ is the Reynolds number of the pipe flow defined in Equation (21).

$$
\operatorname{Re}=\frac{2 m_{f}}{\pi \mu r_{i}}
$$

where, $\mu$ is the dynamic viscosity of the fluid.

\subsection{Entropy generation calculation}

Entropy generation is a term used to evaluate the irreversibility losses of a heat exchanger. The entropy generation rate caused by the finite temperature difference $\left(S_{g e n, \Delta T}\right)$ can be expressed as follows [22]:

$$
S_{g e n, \Delta T}=\frac{Q \Delta T}{T_{f, m}^{2}(1+\chi)}
$$

where, $\chi$ is a dimensionless temperature difference defined by Equation (23) and can be negligible on the thermodynamic temperature scale [22], $T_{f, m}$ is the average temperature of the fluid expressed in Equation (24) and can be regarded as a convenient representative average fluid bulk temperature in the duct, and $\Delta T$ is the temperature difference between the average temperature of the fluid $\left(T_{f, m}\right)$ and the borehole wall $\left(T_{b}\right)$ [22].

$$
\begin{gathered}
\chi=\frac{\Delta T}{T_{f, m}} \\
T_{f, m}=\frac{T_{f, 1}-T_{f, 2}}{\ln \frac{T_{f, 1}}{T_{f, 2}}}
\end{gathered}
$$


For an incompressible fluid under non-adiabatic condition, the irreversibility is only caused by the fluid friction and is expressed by Equation (25). The total entropy generation rate in $\mathrm{U}$ tube heat exchangers can be written as Equation (26):

$$
\begin{gathered}
S_{g e n, \Delta P}=\frac{m_{f, t o t} \Delta P}{\rho_{f} T_{f, m}} \\
S_{g e n}=S_{g e n, \Delta T}+S_{g e n, \Delta P} \\
=\frac{Q \Delta T}{T_{f, m}^{2}(1+\chi)}+\frac{m_{f, t o t} \Delta P}{\rho_{f} T_{f, m}}
\end{gathered}
$$

where, $m_{f, t o t}$ is the total mass flow rate of the system.

Equation (26) can be further simplified to derive the analytical expressions for the determination of the optimal total length and optimal flow rate of vertical U-tube GHEs in terms of the entropy generation rate, and more detailed generation process of the total entropy generation rate can be found in [21].

\section{Case study and test results}

\subsection{Illustrative example}

The schematic of the system studied is shown in Fig. 2, in which a GSHP with the design cooling load of $15 \mathrm{~kW}$ is considered and the vertical U-tube heat exchangers are used. It is worthwhile to note that this GSHP system is a part of the hybrid GSHP system implemented in the Sustainable Buildings Research Centre at University of Wollongong, Australia. The hybrid GSHP system consists of an air source heat pump and two identical water-to-water heat pumps to provide heating and cooling necessary to maintain desired indoor thermal comfort. The two water-to-water heat pumps are connected to a ground loop system, which consists of three vertical borehole heat exchangers and a total of twelve horizontal linear heat exchangers [35]. For simplification of the optimization process, only the vertical borehole heat exchangers are considered in this study. The specifications of the system studied and design conditions are shown in Table 2. 


\subsection{Results from sensitivity analysis}

Based on the design conditions and the ranges of design parameters provided in Table 1 and Table 2, the global sensitivity analysis is used to assess the relative sensitivity of 11 design parameters (see Table 1) on the objective function. As mentioned earlier, the ranges of these parameters are determined based on the practical engineering projects. Through using the extensive Sobol' method with Monte Carlo simulations, the design parameters can be classified into two groups. One is the parameters to be rather insensitive and called low sensitive parameters. In order to reduce the complexity of the GA search space and save computational time, this group of parameters will not be optimized in the entropy generation minimization (EGM)-based global optimization process and the constant values based on good design practices will be assigned for these parameters. The other group of design parameters is sensitive parameters and the changing of these parameters has relative high effects on the dimensionless entropy generation number (EGN). These parameters will be used as the decision variables and are to be optimized in the EGM-based optimization process.

For each design parameters studied, the sensitivity index of the entropy generation number (EGN) of the vertical GHEs with respect to the changes of the design parameters is calculated. The results from the global sensitivity analysis are summarized in Fig. 3. It can be observed that the pipe material conductivity $\left(k_{p}\right)$, half shank distance $(D)$ and borehole distance $(B)$ do not have significant effects on the model output of the entropy generation number, and can be considered as low sensitive parameters. These parameters will not be optimized in the EGMbased optimization process. Although the soil thermal conductivity $\left(k_{s}\right)$, grout material thermal conductivity $\left(k_{b}\right)$ and undisturbed soil temperature $\left(T_{s, 0}\right)$ are the three important parameters for the EGN of the vertical U-tube GHEs. However, $k_{s}$ and $T_{s, 0}$ can be determined once the construction site has been chosen. The grout material is normally a mixture of bentonite and $\mathrm{S}_{i} \mathrm{O}_{2}$ sand, and its thermal conductivity is normally around $2.04-2.42(\mathrm{~W} / \mathrm{mK})$ 
[28]. Therefore, these three parameters are not optimized by the EGM optimization in this study as well. The values of the low sensitive parameters and the construction site related parameters used in this study are summarized in Table 3, which are the recommendation values from practical engineering projects $[28,29]$. The other parameters will be globally optimized by the GA optimizer.

Fig. 4 presents the variations of the entropy generation number (EGN) with respect to the change of the five design parameters to be optimized by the EGM-based optimization process while keeping other parameters constant, which was based on the values of the parameters for the base design case provided in Table 4 and the variation ranges of each design parameter presented in Table 1. Fig. 4a shows the existence of the optimal mass flow rate $\left(m_{f}\right)$ per Utube for minimizing the EGN. From Fig. 4b-4d, it can be found that, with the increase of the borehole number $(N)$, borehole depth $\left(L_{b}\right)$ and pipe outer radius $\left(r_{o}\right)$, the entropy generation number (EGN) decreases. As shown in Fig. 4e, the EGN decreases with the decrease of borehole radius $\left(r_{b}\right)$. The reason is that the thermal performance of the vertical GHEs increases with the increase of the borehole depth $\left(L_{b}\right)$ and pipe outer radius $\left(r_{o}\right)$, and the decrease of borehole radius $\left(r_{b}\right)$ [35]. All the above results indicate that the undesirable thermodynamic irreversibility quantified by the entropy generation number decreases the thermal performance of the vertical U-tube GHE.

\subsection{Result from the entropy generation minimization (EGM) optimization}

For the given example with the design conditions, the selected parameters are globally optimized using genetic algorithm toolbox of MATLAB [26]. According to the ranges of the design variables, an initial random population is generated to carry out the iterative search process. The maximum number of generations used is 100 , which was determined based on many trial tests. The normalized geometric selection, arithmetic crossover and adaptive feasible mutation were employed in the GA optimizer. The variances of the fitness function 
are shown in Fig. 5. It can be found that the fitness value was basically stable after 50 generations, and reached the optimum when the termination condition is met. After 100 generations, the optimal solution of the vertical GHE optimization design problem is obtained and the results are summarized in Table 4 together with the results of the original design (i.e. base design case). The entropy generation numbers of the base design case and optimal design case are 0.2180 and 0.1913 , respectively. Compared to the base design case, a $12.2 \%$ reduction in the entropy generation number value can be achieved by using the optimal design values.

\subsection{Economic analysis}

In order to validate the effectiveness of the proposed EGM-based design optimization method for the vertical U-tube GHEs, an economic analysis was performed for the optimal design and base design. The first upfront cost (IC) and operating cost (OC) were determined based on the cost data shown in Table 5, which was provided by GeoExchange Australia Pty Ltd. The total system cost (TSC) of the 10 years operation of the concerned GSHP systems is used as the performance indictor and expressed in Equation (27). For ground heat exchangers, the upfront cost can be determined by Equation (28). For the water-to-water heat pump, the upfront cost can be determined by Equation (29) and the operation cost can be determined by Equation (30).

$$
\begin{gathered}
T S C=I C_{G H E}+I C_{H P}^{t o t}+O C_{H P} \\
I C_{G H E}=C_{p} L_{p}+C_{b} L_{t o t} \\
I C_{H P}^{t o t}=I C_{H P} N_{H P} \\
O C_{H P}=C_{H P} P_{t o t}
\end{gathered}
$$

where, $I C$ is the upfront cost, $O C$ is the 10 years operation cost, $C_{p}$ is the cost of U-tube per meter, and $C_{b}$ is the drilling and grouting cost of per borehole per meter, $L_{t o t}$ is the total 
borehole length which is calculated by multiplying the borehole number and depth, and $L_{p}$ is the U-tube length within one borehole.

In order to facilitate the economic analysis, a simulation platform representing the real vertical GSHP system shown in Fig. 2, was developed by using TRNSYS and is illustrated in Fig. 6. In the simulation platform, the major component models used were the mathematical models provided in the standard TRNSYS library. The key component models used are the water-to-water heat pump model (Type 927), vertical U-tube GHE model (Type 557), and water pump model (Type 110).

Fig. 7 shows the heating and cooling loads associated to the vertical GSHP system, which were estimated based on the total building loads simulated in the previous study and the load ratio of the vertical system at the design condition [35]. Based on the estimated building load profiles and Sydney weather conditions illustrated in Fig. 8, the annual maximum entering water temperature to the water-to-water heat pump and the variation of the annual energy consumption of the GSHP system with the vertical U-tube GHEs in 10 years of operation of the two cases can be estimated and the results are shown in Fig. 9 and Fig. 10. It is obviously shown that the annual maximum entering water temperature to the water-to-water heat pump in the optimal design case is larger than that in base design case. This is due to that the reduction of the total borehole length $\left(L_{t o t}\right)$ results in the increase of the heat flux in the optimal design case. The increase of the heat flux tends to increase the circulating fluid temperature in the vertical U-tube GHEs. The increase of the entering water temperature leads to the increase of the energy consumption of the water-to-water heat pump in the cooling operation condition, which can be derived from Equations (15)-(17).

The results of the economic analysis for the optimal design case and the base design case are summarized in Table 6. It is clearly shown that the total system cost (i.e. the upfront cost and 10 -year operation cost)) for the optimal design case is $5.5 \%$ lower than the base design 
case. However, the operation cost for the optimal design case is $1.67 \%$ higher than that of the base design case, while the upfront cost of the optimal design case is $7.2 \%$ lower than the base design case.

Fig. 11 presents the relationships between the entropy generation number and the economic aspects for the GSHP with vertical U-tube GHEs under different entropy generation numbers. The entropy generation numbers were obtained from the EGM-based optimization process. From Fig. 11, it can be observed that the operation cost slightly increases, while the total system cost and upfront cost decrease, with the increase of the entropy generation number. From the thermodynamic aspect, the smaller of the entropy generation number, the better the thermal performance of the vertical U-tube GHEs. However, from the economic aspects, it seems that a relatively larger value of the entropy generation number will decrease the upfront cost in the case studied. Therefore, it is necessary to optimize the entropy generation number by taking into account both the thermodynamic and economic aspects when using entropy generation minimization method to design vertical ground heat exchangers.

\section{Conclusion}

In this paper, a new method for optimal design of vertical U-tube ground heat exchangers was proposed. The new method was developed based on the entropy generation minimization (EGM) by using genetic algorithms. In this method, the entropy generation number was used as the objective function, and a genetic algorithm optimization technique was applied to solve the optimization problems.

The performance of the proposed new design method was evaluated through a case study. All major design parameters were categorized into two groups, i.e. low sensitive parameters and high sensitive parameters, through the global sensitivity analysis. The entropy generation minimization (EGM)-based optimization is used to globally optimize the high sensitive 
parameters, including number of boreholes, borehole depth, outer pipe diameter, borehole radius, and circulating fluid mass flow rate per pipe. The results showed that the total system cost (i.e. the upfront cost and 10-year operation cost) of the system studied with the decision parameters optimized by the EGM optimization was $5.5 \%$ lower than that of using the original design parameters. The results also demonstrated the importance of integrating the entropy generation minimization method with economic analysis for optimal design of ground source heat pump systems.

\section{Acknowledgement}

The authors would like to thank Mr Yale Carden, Managing Director of GeoExchange Australia Pty Ltd for valuable discussions/suggestions and providing the cost data for the installation of the ground source heat pump systems in Australia.

\section{References}

[1] Kharseha M, Altorkmanyb L, Al-Khawaja M, Hassanic F. Warming impact on energy use of HVAC system in buildings of different thermal qualities and in different climates. Energy Convers Manage 2014;81:106-11.

[2] Bhaskoro PT, Haq Gilani SI UI, Aris MS. Simulation of energy saving potential of a centralized HVAC system in an academic building using adaptive cooling technique. Energy Convers Manage 2014;75:617-28.

[3] Ma ZJ, Wang SW. Enhancing the performance of large primary-secondary chilled water systems by using bypass check valve. Energy 2011;36:268-76. 
[4] Self SJ, Reddy BV, Rosen MA. Geothermal heat pump systems: Status review and comparison with other heating options. Appl Energy 2013;101:341-8.

[5] Urchueguíaa JF, Zacarésa M, Corberána JM, Monteroa Á, Martosb J, Wittec H. Comparison between the energy performance of a ground coupled water to water heat pump system and an air to water heat pump system for heating and cooling in typical conditions of the European Mediterranean coast. Energy Convers Manage 2012;49:291723.

[6] Man Y, Yang HX, Wang JG. Study on hybrid ground-coupled heat pump system for airconditioning in hot-weather areas like Hong Kong. Appl Energy 2010;87:2826-33.

[7] Benli H, Durmuş A. Evaluation of ground-source heat pump combined latent heat storage system performance in greenhouse heating. Energy Build 2009;41:220-8.

[8] Yang H, Cui P, Fang ZH. Vertical borehole ground source heat pumps: A review of models and systems. Appl Energy 2010;87(1):16-27.

[9] Goetzler W, Guernsey M, Kar R. Research and development roadmap: Geothermal (ground-source) heat pumps. U.S. Department of Energy, Energy Efficiency and Renewable Energy, October 2012.

[10] Garber D, Choudhary R, Soga K. Risk based lifetime costs assessment of a ground source heat pump (GSHP) system design: Methodology and case study. Build Environ 2013;60:66-80.

[11] Zogou O, Stamatelos A. Optimization of thermal performance of a building with ground source heat pump system. Energy Convers Manage 2007;48(11):2853-63.

[12] Yu X, Zhai XQ, Wang RZ. Design and performance of a constant temperature and humidity air-conditioning system driven by ground source heat pumps in winter. Energy Convers Manage 2010;51:2162-8. 
[13] Pertzborn A, Nellis G, Klein S. Impact of weather variation on ground-source heat pump design. HVAC\&R Res 2011;17:174-85.

[14]Capozza A, Carli MD, Zarrella A. Design of borehole heat exchangers for ground-source heat pumps: A literature review, methodology comparison and analysis on the penalty temperature. Energy Build 2012; 55:369-79.

[15] Alavy M, Nguyen Hiep V, Leong Wey H, Dworkin Seth B, A methodology and computerized approach for optimizing hybrid ground source heat pump system design. Renew Energy 2013;57:404-12.

[16] Robert F, Gosselin L. New methodology to design ground coupled heat pump systems based on total cost minimization. Appl Therm Eng 2014;62(2):481-91.

[17] Hepbasli A, Akdemir O. Energy and exergy analysis of a ground source (geothermal) heat pump system. Energy Convers Manage 2004;45(5):737-53.

[18] Bi YH, Wang XH, Liu Y, Zhang H, Chen LG. Comprehensive exergy analysis of a ground-source heat pump system for both building heating and cooling modes. Appl Energy 2009;86:2560-5.

[19] Sayyaadi H, Amlashi EH, Amidpour M. Multi-objective optimization of a vertical ground source heat pump using evolutionary algorithm. Energy Convers Manage 2009;50:2035-46.

[20] Sayyaadi H, Nejatolahi M. Thermodynamic and thermoeconomic optimization of a cooling tower-assisted ground source heat pump. Geothermics 2011;40(3):221-32.

[21] Li M, Lai AKC. Thermodynamic optimization of ground heat exchangers with single Utube by entropy generation minimization method. Energy Convers Manage 2013;65:1339.

[22] Bejan A. Entropy generation minimization: the method of thermodynamic optimization of finite-size systems and finite-time processes. Boca Raton: CRC Press Inc.; 1996. 
[23] Cheng XT, Liang XG. Discussion on the applicability of entropy generation minimization and entransy theory to the evaluation of thermodynamic performance for heat pump systems. Energy Convers Manage 2014;80:238-42.

[24] Gutiérrez F, Méndez F. Entropy generation minimization for the thermal decomposition of methane gas in hydrogen using genetic algorithms. Energy Convers Manage 2012;55:1-13.

[25] Ma ZJ, Wang SW. Testing and evaluation of energy saving potentials in a complex building central chilling system using genetic algorithm. Building Services and Engineering Research and Technology 2011;32:109-26.

[26] Houck CR, Joines J, Key M, A genetic algorithm for function optimization: a Matlab implementation. ACM Transactions on Mathematical Software, 1996.

[27] Chachuata B, Srinivasanb B, Bonvin D. Model parameterization tailored to real-time optimization. Compute \& Chemic Eng 2008;25:1-13.

[28] ASHRAE. HVAC applications. SI Edition.; 2011.

[29]Banks D. An introduction to thermogeology: ground source heating and cooling. $2^{\text {nd }}$ ed. John Wiley \& Sons, Inc.; 2012.

[30] Cannavó F. Sensitivity analysis for volcanic source modelling quality assessment and model selection. Computers \& Geoscience 2012;44:52-9.

[31]Fesangharya M, Damangira E, Soleimani I. Design optimization of shell and tube heat exchangers using global sensitivity analysis and harmony search algorithm. Appl Therm Eng 2009;29:1026-31.

[32] Lamarche L, Kajl S, Beauchamp B. A review of methods to evaluate borehole thermal resistances in geothermal heat-pump systems. Geothermics 2010;39(2):187-200.

[33] Sanaye S, Niroomand B. Thermal-economic modelling and optimization of vertical ground-coupled heat pump. Energy Convers Manage 2012;50:1-13. 
[34]Bejan A. Convective heat transfer. $3^{\text {rd }}$ ed. Hoboken: John Wiley \& Sons, Inc.; 2004.

[35]Huang S, Ma ZJ, Cooper P. Evaluation of a ground source heat pump system in a netzero energy office building. In: 12th International Conference on Sustainable Energy Technologies, Hong Kong; 2013. p.1-9. 


\section{Tables}

Table 1 Ranges of design parameters of the vertical U-tube heat exchangers [28, 29]

\begin{tabular}{c|c|c}
\hline & Design parameters & Values or ranges \\
\hline & Number of boreholes: $N$ & {$\left[1, \frac{Q_{\text {tot }}}{q_{\min } L_{b, \min }}\right]$} \\
Vertical U- & Borehole depth $L_{b}(\mathrm{~m})$ & {$[50,200]$} \\
tube GHE & Borehole distance $B(\mathrm{~m})$ & {$[3,10]$} \\
geometry & Borehole radius $r_{b}(\mathrm{~m})$ & {$[0.0325,0.1]$} \\
parameters & Pipe outer radius $r_{o}(\mathrm{~m})$ & {$[0.012,0.022]$} \\
& Half shank space D $(\mathrm{m})$ & {$\left[0, \mathrm{r}_{\mathrm{b}}-2 \mathrm{r}_{\mathrm{o}}\right]$} \\
\hline \multirow{2}{*}{ Material } & Pipe material conductivity $k_{p}(\mathrm{~W} / \mathrm{mK})$ & {$[0.2,0.6]$} \\
parameters & Grout material conductivity $k_{b}(\mathrm{~W} / \mathrm{mK})$ & {$[0.5,2.5]$} \\
& Soil material conductivity $k_{s}(\mathrm{~W} / \mathrm{mK})$ & {$[0.5,2.5]$} \\
\hline \multirow{2}{*}{ Operating } & Circulating fluid mass flow rate per pipe $m_{f}(\mathrm{~kg} / \mathrm{s})$ & {$[0.1,1]$} \\
conditions & Undisturbed soil temperature $T_{s, 0}\left({ }^{\circ} \mathrm{C}\right)$ & {$[10,20]$} \\
\hline
\end{tabular}

Table 2 Specifications of the system studied and design conditions

\begin{tabular}{c|l|c}
\hline \multirow{4}{*}{ Design condition } & Design cooling load $(\mathrm{kW})$ & 15 \\
& Indoor design temperature $\left({ }^{\circ} \mathrm{C}\right)$ & 24 \\
& Outdoor design temperature $\left({ }^{\circ} \mathrm{C}\right)$ & 31 \\
& Average undisturbed soil temperature $\left({ }^{\circ} \mathrm{C}\right)$ & 20 \\
\hline \multirow{2}{*}{$\begin{array}{c}\text { Water-water heat } \\
\text { pump }\end{array}$} & Rated cooling capacity/power consumption $(\mathrm{kW} / \mathrm{kW})$ & $16.4 / 4.1$ \\
& Rated heating capacity/power consumption $(\mathrm{kW} / \mathrm{kW})$ & $20.4 / 5.5$ \\
\hline
\end{tabular}

Table 3 Low sensitive parameters and the values used [28, 29]

\begin{tabular}{|c|c|c|}
\hline Parameters & Values & Units \\
\hline Pipe material conductivity $\left(k_{p}\right)$ & 0.5 & $\mathrm{~W} / \mathrm{mK}$ \\
\hline Borehole distance $(B)$ & 8 & $\mathrm{~m}$ \\
\hline Half shank space : $(D)$ & $r_{b}-2 r_{o}$ & $\mathrm{~m}$ \\
\hline Soil material conductivity $\left(k_{s}\right)$ & 2.0 & $\mathrm{~W} / \mathrm{mK}$ \\
\hline $\begin{array}{l}\text { Grout material thermal } \\
\text { conductivity }\left(k_{b}\right)\end{array}$ & 2.42 & $\mathrm{~W} / \mathrm{mK}$ \\
\hline $\begin{array}{l}\text { Undisturbed soil temperature } \\
\left(T_{S, 0}\right)\end{array}$ & 20 & ${ }^{\circ} \mathrm{C}$ \\
\hline
\end{tabular}


Table 4 Original and optimal design parameters of the vertical U-tube GHEs

\begin{tabular}{cccccccc}
\hline Case & $\begin{array}{c}r_{b} \\
(\mathrm{~m})\end{array}$ & $\begin{array}{c}m_{f} \\
(\mathrm{~kg} / \mathrm{s})\end{array}$ & $\begin{array}{c}L_{b} \\
(\mathrm{~m})\end{array}$ & $N$ & $\begin{array}{c}r_{o} \\
(\mathrm{~m})\end{array}$ & EGN & $\begin{array}{c}\text { EGN reduction } \\
(\%)\end{array}$ \\
\hline Base design & 0.075 & 0.4 & 91 & 3 & 0.020 & 0.2180 & - \\
Optimal design & 0.06 & 0.595 & 126 & 2 & 0.016 & 0.1913 & 12.2 \\
\hline
\end{tabular}

Table 5 Installation cost for borehole heat exchangers

\begin{tabular}{l|cc}
\hline \multicolumn{1}{c|}{ Component } & \multicolumn{2}{c}{ Cost } \\
\hline U-shaped polyethylene pipe & \multicolumn{2}{c}{} \\
\hline 40mm Outer Diameter & $3.07 \quad(\$ / \mathrm{m})$ \\
32mm Outer Diameter & $2.10 \quad(\$ / \mathrm{m})$ \\
\hline Drilling cost & 75 & $(\$ / \mathrm{m})$ \\
\hline Grouting cost & 8 & $(\$ / \mathrm{m})$ \\
\hline Water-to-water heat pump & 6000 & $(\$ / \mathrm{unit})$ \\
\hline Electricity price & $0.25 \quad(\$ / \mathrm{kWh})$ \\
\hline
\end{tabular}

Table 6 Economic cost analysis of systems of two design cases

\begin{tabular}{l|c|c}
\hline & Base case & Optimal case \\
\hline Number of boreholes & 3 & 2 \\
\hline Borehole depth $(\mathrm{m})$ & 91 & 126 \\
\hline Outer pipe diameter $(\mathrm{m})$ & 0.040 & 0.032 \\
\hline Borehole radius $(\mathrm{m})$ & 0.075 & 0.06 \\
\hline $\begin{array}{l}\text { Energy consumption in 10 years } \\
\text { operation }(\mathrm{kWh})\end{array}$ & $29,844.4$ & $30,340.8$ \\
\hline 10 years operating cost $(\$)$ & $7,461.1$ & $7,585.2$ \\
\hline Total upfront cost $(\$)$ & $30,335.2$ & $28,148.8$ \\
\hline $\begin{array}{l}\text { Total system cost (i.e. Upfront cost } \\
\text { and } 10 \text { years operation cost) }(\$)\end{array}$ & $37,796.3$ & $35,734.0$ \\
\hline Total system cost savings $(\%)$ & - & 5.5 \\
\hline
\end{tabular}




\section{Figures}

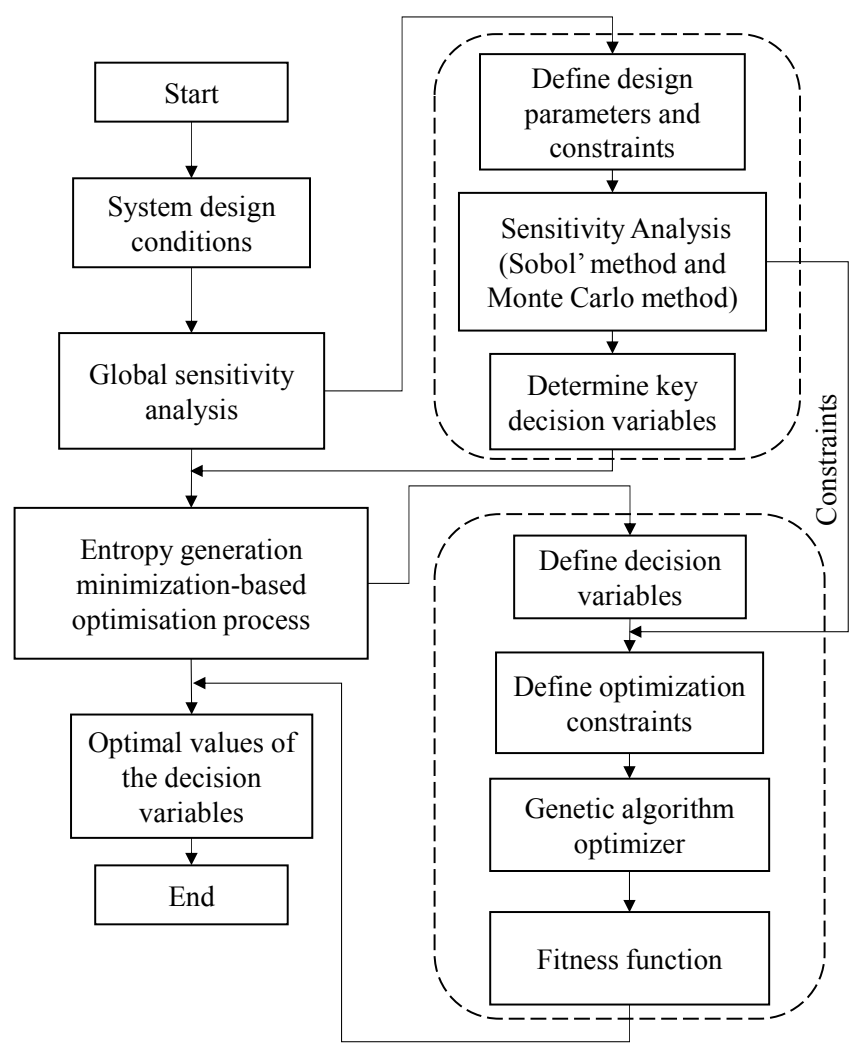

Fig. 1 Outline of the design optimization methodology.

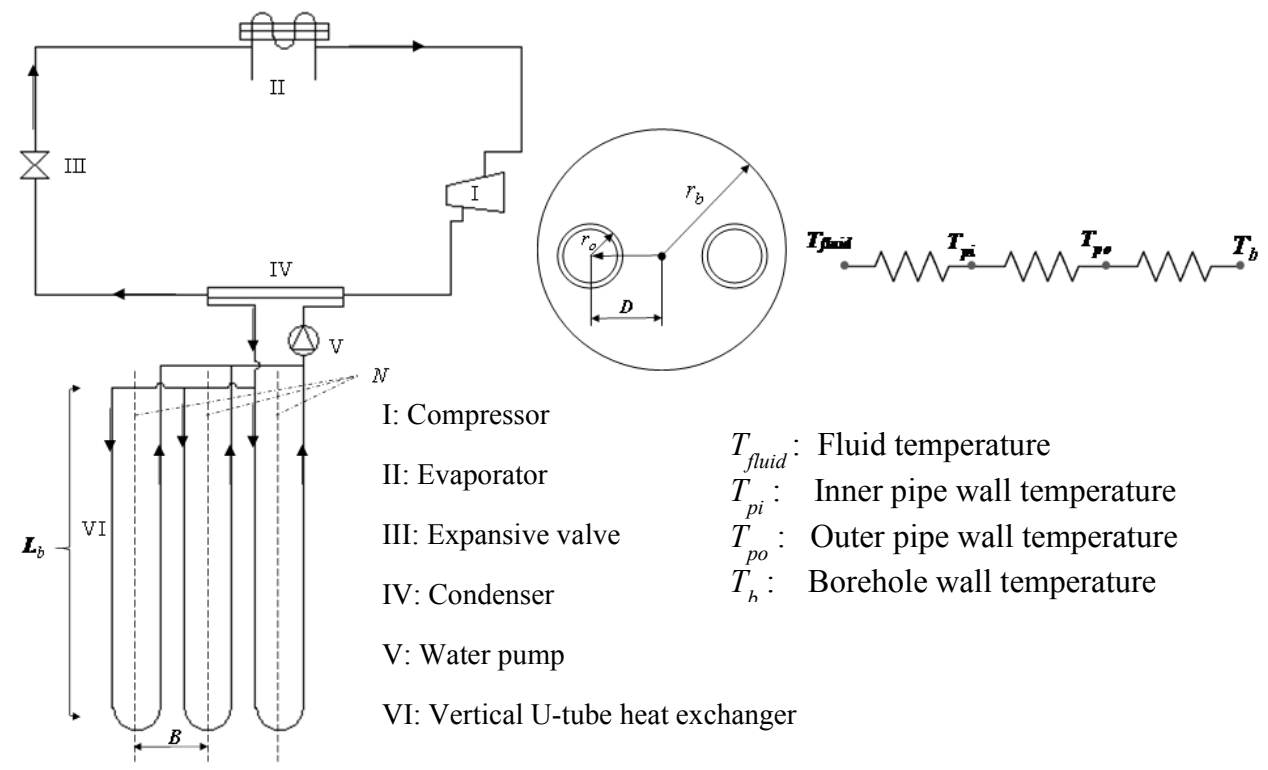

Fig. 2 Schematic of the vertical ground source heat pump. 


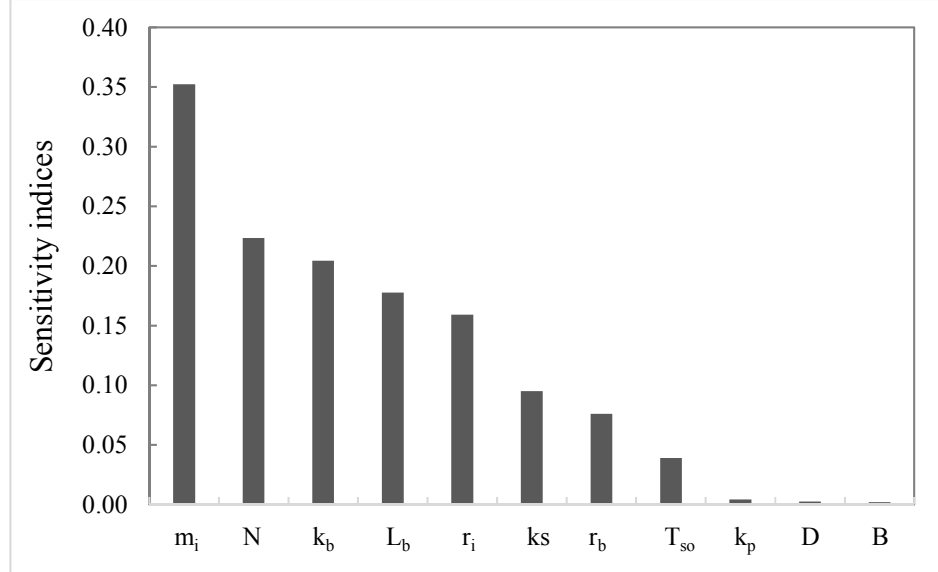

Fig. 3 Sensitivity indices of the EGN for different design parameters. 


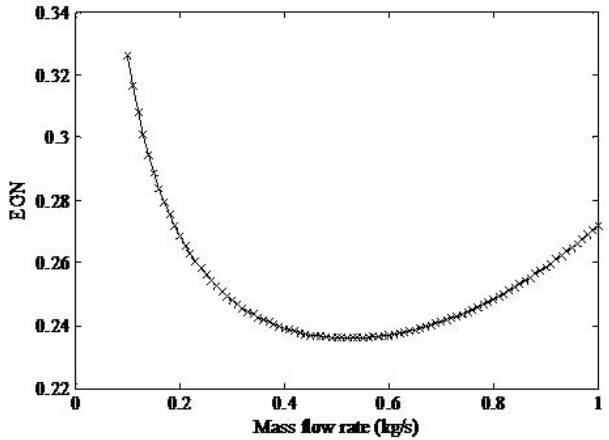

(a) EGN versus mass flow rate

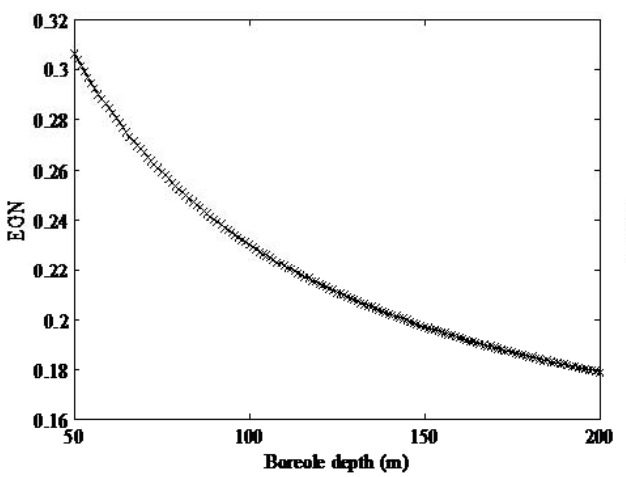

(c) EGN versus borehole depth

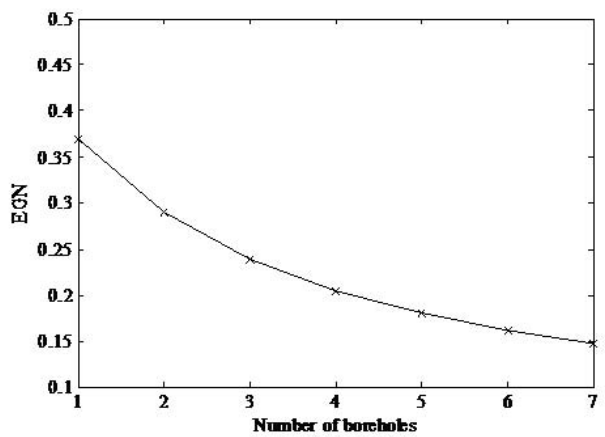

(b) EGN versus borehole numbers

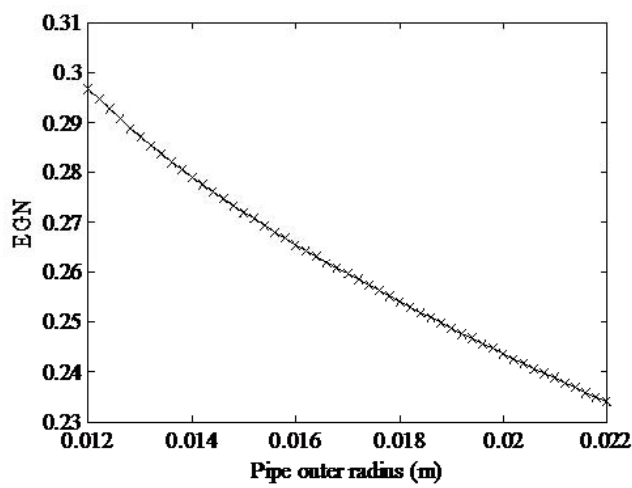

(d) EGN versus pipe outer radius

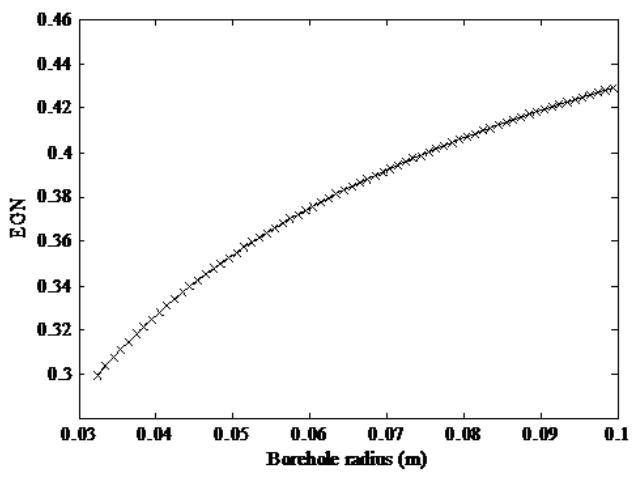

(e) EGN versus borehole radius

Fig. 4 Variations of the entropy generation number for high sensitive parameters. 


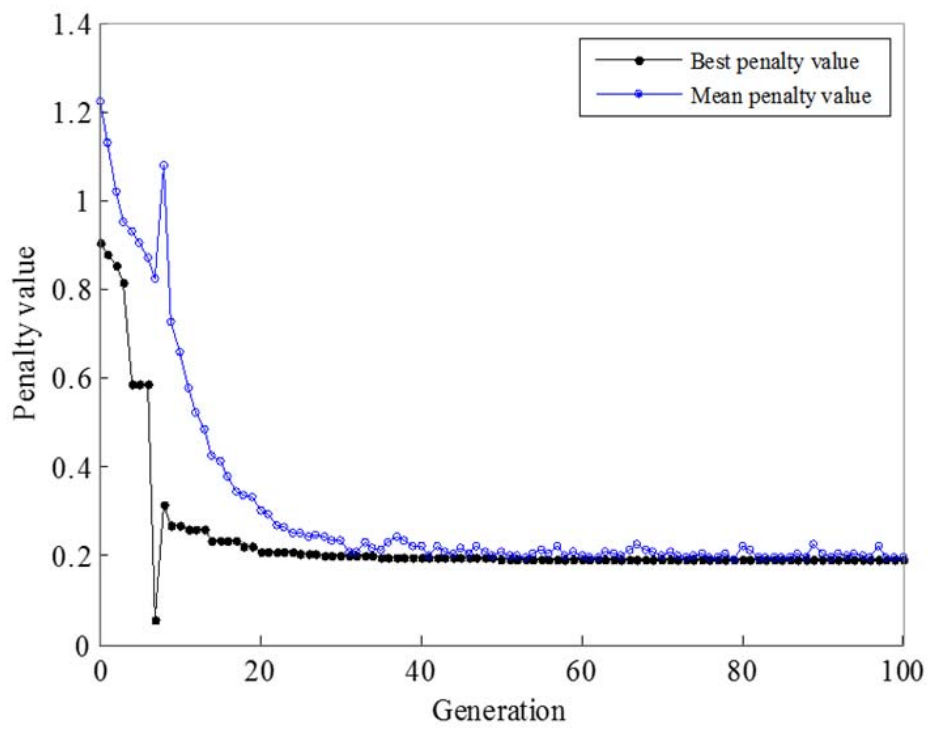

Fig. 5 Variations of the penalty value of the best individual in each generation.

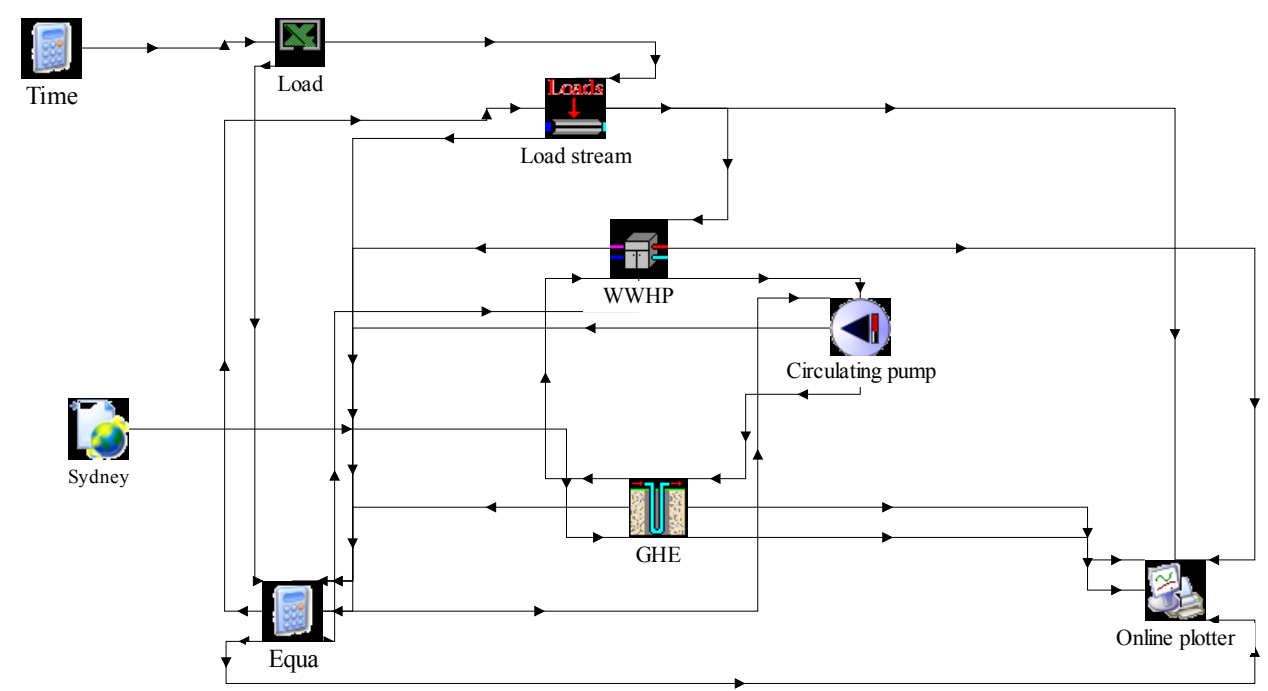

Fig. 6 Illustration of the simulation platform developed by TRNSYS. 


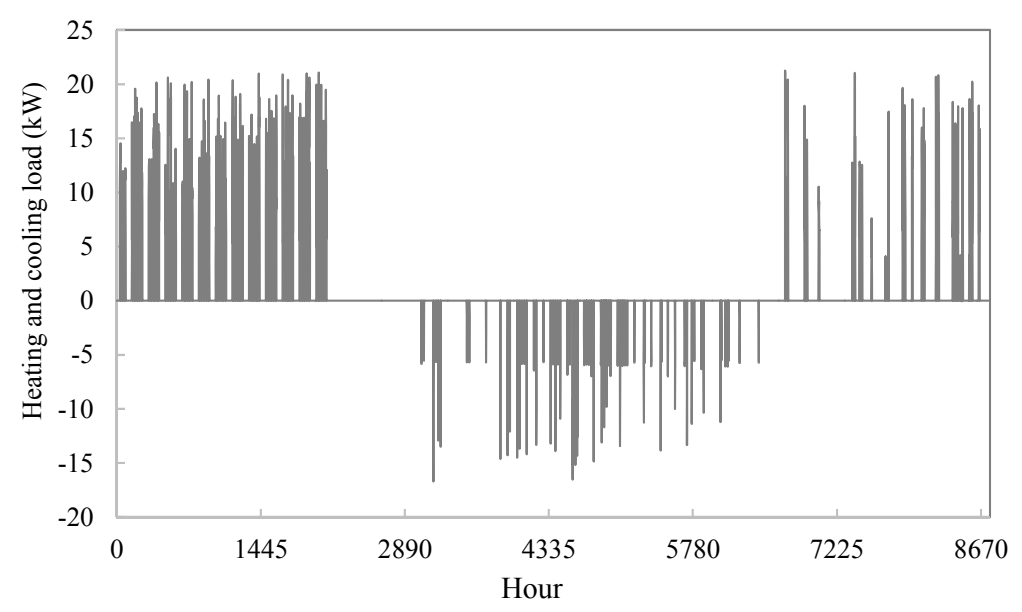

Fig. 7 Heating and cooling load profile for the vertical GSHP.

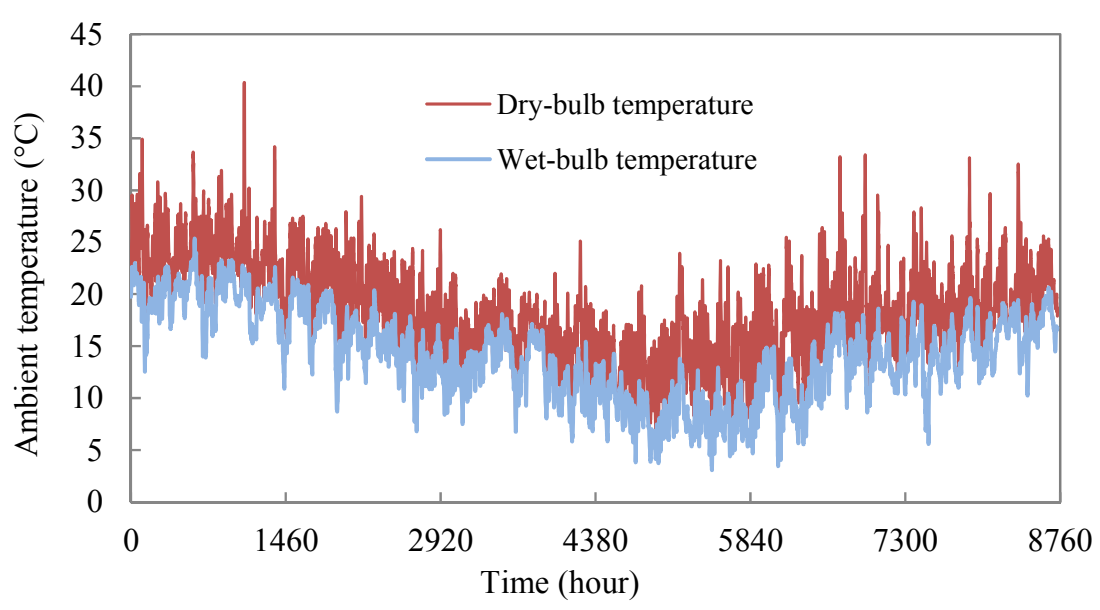

Fig. 8 Ambient air dry-bulb and wet-bulb temperatures in Sydney, Australia.

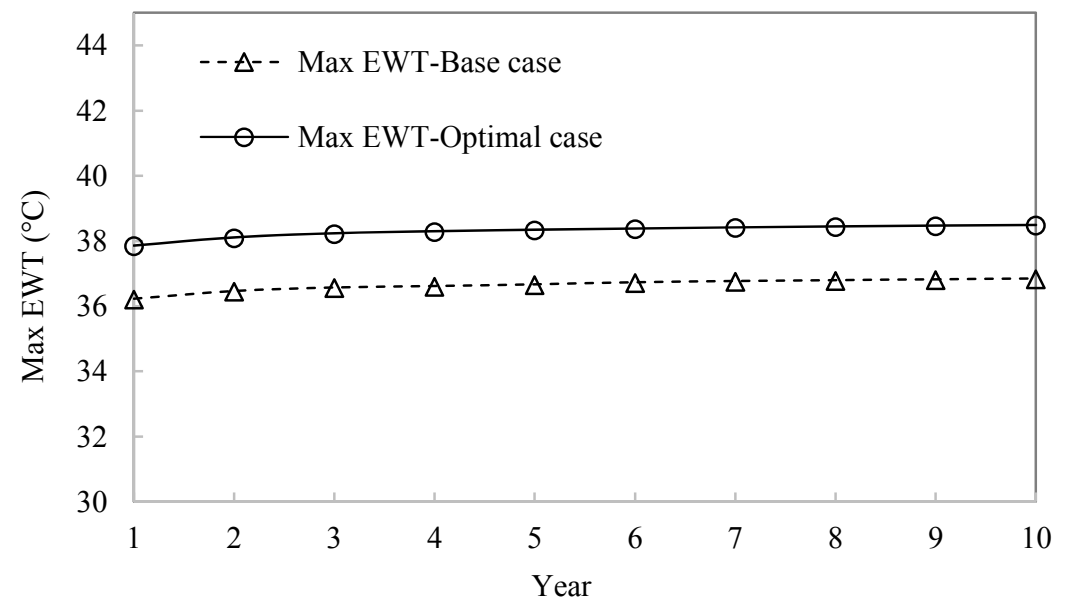


Fig. 9 Annual maximum entering water temperature (EWT) to the water-to-water heat pump in 10 years operation.

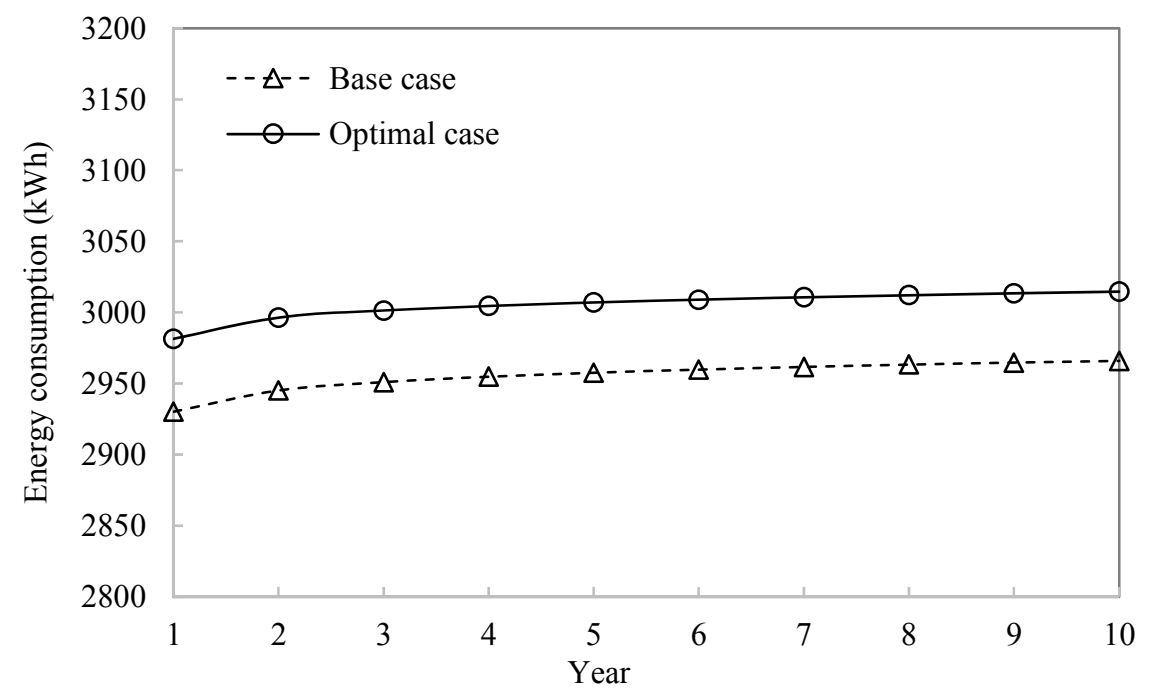

Fig. 10 Annual energy consumption of the vertical GSHP in 10 years operation.

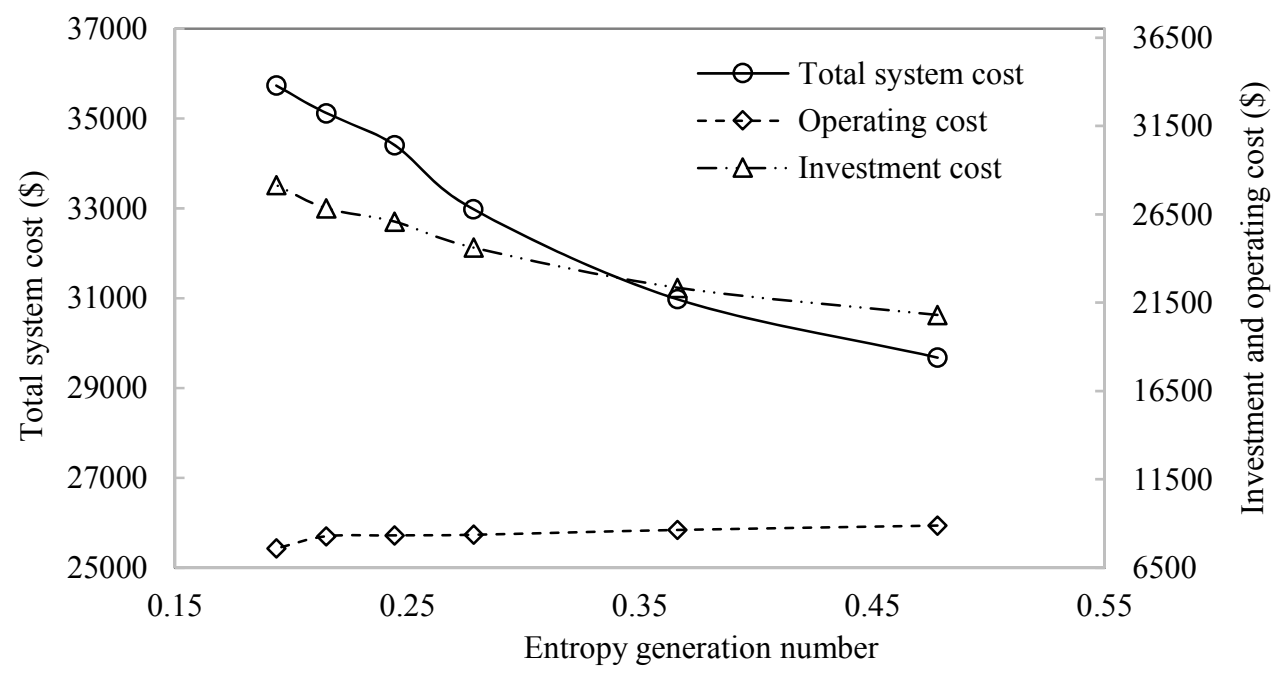

Fig. 11 Variations of the entropy generation number with respect to the total system cost, upfront cost and operating cost of the vertical GSHP. 